\title{
New Genotypes of Fusarium oxysporum f. sp. vasinfectum from the Southeastern United States
}

E. A. Holmes, Department of Plant Pathology, University of California, Davis 95616; R. S. Bennett and D. W. Spurgeon, Western Integrated Cropping Systems Research Unit, United States Department of AgricultureAgricultural Research Service, Shafter, CA 93263; P. D. Colyer, Louisiana Agricultural Experiment Station, Red River Research Station, Bossier City 71113-8550; and R. M. Davis, Department of Plant Pathology, University of California, Davis

\begin{abstract}
Holmes, E. A., Bennett, R. S., Spurgeon, D. W., Colyer, P. D., and Davis, R. M. 2009. New genotypes of Fusarium oxysporum f. sp. vasinfectum from the southeastern United States. Plant Dis. 93:1298-1304.

Sixty-one isolates of Fusarium oxysporum f. sp. vasinfectum were collected from cotton plants (Gossypium spp.) with symptoms of Fusarium wilt to determine the composition of races present in the southeastern United States. Analysis of partial sequences of the translation elongation factor gene revealed four novel genotypes, as well as the presence of races 3 and 8 for the first time in the United States outside of California. The majority of isolates (16 of 27) sampled from Arkansas were novel genotypes. A subset of isolates representing the novel genotypes was compared with previously described races using sequences from translation elongation factor, phosphate permase, and $\beta$-tubulin genes and their pathogenicity on a total of six Upland (Gossypium hirsutum) and Pima ( $G$. barbadense) cotton cultivars. Two of the novel genotypes belonged to a clade containing races $1,2,4,6$, and 8 and two shared ancestry with race 3 . All new genotypes were pathogenic to at least some of the cotton cultivars tested. The Pima cv. Phytogen 800 was relatively resistant to all genotypes of the pathogen. These results indicate that the population of F. oxysporum f. sp. vasinfectum in the southeastern United States is more diverse than previously recognized.
\end{abstract}

When available, host plant resistance is an integral tool for managing soilborne diseases. Effective development and deployment of resistant cultivars are facilitated by knowledge of the diversity and distribution of pathogen pathotypes. Plant breeders and growers can respond more effectively to arrivals of exotic pathotypes if the responses of widely planted cultivars to described pathotypes are known. A case in point is race 4 of Fusarium oxysporum f. sp. vasinfectum W.C. Snyder \& H.N. Hansen, a cause of Fusarium wilt in cotton (Gossypium spp.) in the San Joaquin Valley of California. Upon the discovery of race 4 in 2001 (18), an extensive collection of available Upland (Gossypium hirsutum

Corresponding author: R. M. Davis

E-mail: rmdavis@ucdavis.edu

GenBank accession numbers: FJ466731-FJ466745.

Mention of trade names or commercial products in this article is solely for the purpose of providing specific information and does not imply recommendation or endorsement by the United States Department of Agriculture, the University of California, or Louisiana State University Agricultural Center.

Accepted for publication 25 July 2009.

doi:10.1094/PDIS-93-12-1298

(C) 2009 The American Phytopathological Society
L.) and Pima (G. barbadense L.) germplasm was screened for resistance to this resistant commercial Pima cultivar and documented moderate resistance in Upland cultivars (24). Race 4 was probably introduced to the United States from Asia, given the genetic similarity of the California isolates to isolates of race 4 which were first described in 1960 (4,18). San Joaquin Valley cotton growers have since increased production of the resistant $\mathrm{cv}$. Phytogen 800 (Dow AgroSciences, Indianapolis, IN), which represented $74 \%$ of the Pima production in the state in 2008 (25).

The first races of $F$. oxysporum f. sp. vasinfectum were described in 1958 and distinguished between isolates capable of causing wilt symptoms in soybean and tobacco (race 2) from isolates that could not (race 1) (6). In total, 8 races have since been reported $(4-6,10,15)$ but analyses of random amplified polymorphic DNA $(1,7)$, amplified fragment length polymorphism (1), and restriction fragment length polymorphism (RFLP) (9) markers; fatty acid profiles (14); multigene genealogies (22); and pathogenicity tests $(7,11)$ indicate potential redundancies in race designations. Races 1, 2, and 6, 3 and 5, and 4 and 7 , are likely to be identical or nearly so. Recently, additional genotypes $(2,11)$ and new distributions of known genotypes $(2,18)$ have been uncovered in addition to pathogen. That work identified a single the discovery of race 4 in California. In the last 15 years, virulent genotypes causing Fusarium wilt of cotton in Australia have developed from endemic $F$. oxysporum associated with native Gossypium spp. (26). A recent study using gene genealogies showed that races 3 and 8 went undetected in California for many years (18). These were the first reports of race 3 in the New World and of race 8 outside of China (10). Finally, several potentially new genotypes of $F$. oxysporum f. sp. vasinfectum were recently described from the Ivory Coast (2). These had unique profiles of restriction enzyme digests of the ribosomal intergenic spacer region-RFLP and new vegetative compatibility groups (2). These reports suggest that much work remains in describing populations of this pathogen.

In the United States, only one nationwide survey of $F$. oxysporum f. sp. vasinfectum races has been made and it was conducted more than 25 years ago (16). That survey differentiated 53 isolates from seven states into races 1 or 2 , which are now known to be genetically similar $(7,13,18,22)$ and pathogenically identical on cotton $(6,7)$. A larger, more comprehensive survey is needed to accurately determine the known distribution of races causing Fusarium wilt in U.S. cotton. As a preliminary step toward understanding the distribution and diversity of $F$. oxysporum f. sp. vasinfectum in the U. S., pathogenicity tests and sequence analyses of multiple genes were used to examine a collection of $F$. oxysporum isolates from symptomatic cotton plants from several southeastern states.

\section{MATERIALS AND METHODS}

Fungal isolates. A total of 61 isolates of $F$. oxysporum f. sp. vasinfectum collected from commercial fields in Arkansas, Georgia, Louisiana, and Missouri between 2002 and 2007 was examined (Table 1). Isolates were obtained from cotton plants exhibiting symptoms typical of Fusarium wilt, including stunted growth, vascular discoloration, and wilt, chlorosis, and necrosis of leaves. Cultures from single spores were stored on silica gel at $4^{\circ} \mathrm{C}$.

DNA isolation, amplification, and sequencing. Methods used for DNA isolation, polymerase chain reaction (PCR) amplification, and sequencing have been 
described previously (18). Mycelium for DNA extraction was obtained from single spore-derived isolates grown in $100 \mathrm{ml}$ of sterile liquid medium containing, per liter, $20.7 \mathrm{~g}$ of D-glucose, $1.2 \mathrm{~g}$ of DLasparagine, $1.2 \mathrm{~g}$ of $\mathrm{K}_{2} \mathrm{HPO}_{4} \cdot 3 \mathrm{H}_{2} \mathrm{O}, 0.5 \mathrm{~g}$ of $\mathrm{MgSO}_{4} \cdot 7 \mathrm{H}_{2} \mathrm{O}, 0.5 \mathrm{~g}$ of yeast extract, and $0.1 \mathrm{~g}$ of $\mathrm{NaCl}$. Cultures were grown at room temperature on a shaker for 4 or 5 days. Mycelium was harvested using Miracloth (EMD Biosciences, San Diego, $\mathrm{CA}$ ), washed with sterile distilled water, with liquid nitrogen. Genomic DNA was extracted with the DNeasy Plant Mini Kit (Qiagen Inc., Valencia, CA) following manufacturer instructions and stored at $-20^{\circ} \mathrm{C}$.

Translation elongation factor (EF-1 $\alpha)$ primers EF-1 (5'ATGGGTAAGGAAGAC AAGAC) and EF-2 (5'GGAAGTACCAGT GATCATGTT) (19) were used to prescreen the 61 isolates for potentially novel genotypes. All isolates from novel genotypes were further examined by amplifying portions of two additional nuclear genes with the following primers: phosphate permase (PHO) PHO-1 (5'ATCTTCTGG CGTGTTATCATG) and PHO-6 (5'GAT and ground to a fine powder after freezing

GTGGTTGTAAGCAAAGCCC) (23), and $\beta$-tubulin (BT) BT-3 (5'CGTCTAGAG GTACCCATACCGGCA) and BT-5 (5'GCT CTAGACTGCTTTCTGGCAGACC) (20). Amplification was conducted in a thermal cycler (PTC-100; MJ Research, Watertown, MA) under the following conditions: 40 cycles of $95^{\circ} \mathrm{C}$ for $30 \mathrm{~s}, 55^{\circ} \mathrm{C}$ for $30 \mathrm{~s}$, and $72^{\circ} \mathrm{C}$ for $1 \mathrm{~min}$, and a final extension of $5 \mathrm{~min}$ at $72^{\circ} \mathrm{C}$ for $\mathrm{EF}-1 \alpha ; 35$ cycles of $94^{\circ} \mathrm{C}$ for $30 \mathrm{~s}, 52^{\circ} \mathrm{C}$ for $30 \mathrm{~s}$, and $72^{\circ} \mathrm{C}$ for $1 \mathrm{~min} 30 \mathrm{~s}$ for $\mathrm{BT}$; and $97^{\circ} \mathrm{C}$ for $1 \mathrm{~min}$ of initial denaturing followed by 35 cycles of $96^{\circ} \mathrm{C}$ for $30 \mathrm{~s}, 50^{\circ} \mathrm{C}$ for $1 \mathrm{~min}$, and $72^{\circ} \mathrm{C}$ for $1 \mathrm{~min}$ followed by a final extension time of $10 \mathrm{~min}$ at $72^{\circ} \mathrm{C}$ for PHO. A negative control of no template DNA was included in each PCR reaction. The PCR products were purified with QIAquick PCR Purification Kits (Qiagen, Inc.) following the manufacturer's protocol. Amplification primers were also used for sequencing fragments in both directions. Sequencing was done at the University of California-Davis DBS Automated DNA Sequencing Facility.

Sequence analyses. Accelrys Seqweb (version 2.1; Accelrys, Madison, WI) was used with the pileup option for aligning

Table 1. Summary of genotypes of Fusarium oxysporum f. sp. vasinfectum from the southeastern United States based on translation elongation factor (EF-1 $\alpha$ ) sequences (19)

\begin{tabular}{llccccccc}
\hline & & \multicolumn{7}{c}{ Genotype $^{\mathbf{a}}$} \\
\cline { 3 - 9 } No. & Origin & Races 1 or 2 & Race 3 & Race 8 & $\mathbf{1 0 8}$ & $\mathbf{1 1 0}$ & $\mathbf{1 1 2}$ & $\mathbf{1 2 7 / 1 4 0}$ \\
\hline 27 & Arkansas & 6 & 0 & 5 & 10 & 1 & 1 & 4 \\
28 & Louisiana & 21 & 3 & 4 & 0 & 0 & 0 & 0 \\
4 & Georgia & 2 & 0 & 1 & 1 & 0 & 0 & 0 \\
2 & Missouri & 0 & 0 & 2 & 0 & 0 & 0 & 0
\end{tabular}

${ }^{a}$ Isolates classified by comparing sequences of the translation EF-1 $\alpha$ gene. Races 1 and 2 generally considered synonymous $(7,22)$.

b Total number of isolates examined from each state. sequences. If necessary, sequences were manually adjusted using MacClade Phylogenetic Software (version 3.0; Sinauer Associates, Inc., Sunderland, MA). Phylogenetic trees were inferred using maximum parsimony in PAUP 4.0b10 (Sinauer Associates, Inc.) with all characters unordered and equally weighted. Gaps were treated as missing data. A saprophytic isolate of $F$. oxysporum (FO1502) from the rhizosphere of melon fruit (Cucurbitaceae) was used as the outgroup. Statistical support for branches was obtained by running 1,000 bootstrap replicates. The final alignment and phylogenetic tree have been deposited in TreeBASE (accession number SN4216).

Pathogenicity tests. The pathogenicity of five isolates arbitrarily selected to represent new genotypes of $F$. oxysporum f. sp. vasinfectum (isolates 108, 110, 112, 127, and 140) was compared with the pathogenicity of previously characterized isolates (races 1, 3, 4, and 8) on six cotton cultivars (Table 2). The experimental design was a randomized complete block with six replications (blocks) conducted in a greenhouse maintained at 18 to $24^{\circ} \mathrm{C}$. Treatments of six cotton cultivars and nine Fusarium isolates plus a water control were tested, with a single potted plant within each block serving as the experimental unit for each of the 60 combinations of cultivar and fungal isolate. Four Upland cultivars ( $G$. hirsutum) - Phytogen 72 (Dow AgroSciences, Indianapolis, IN), DP 445 (Delta and Pine Land Company, Scott, MS), Phytogen 480, and Stoneville 4357 (Bayer CropSciences, Research Triangle Park, NC) - and two Pima cultivars (G. barbadense; Phytogen 800 and DP $744)$ were planted in $12-\mathrm{cm}$-diameter plas-

Table 2. Strains of Fusarium oxysporum f. sp. vasinfectum and a saprophytic F. oxysporum used in phylogenetic analyses of isolates collected from cotton (Gossypium hirsutum) in the southern United States

\begin{tabular}{|c|c|c|c|c|c|}
\hline \multirow[b]{2}{*}{ Isolate ${ }^{b}$} & \multirow[b]{2}{*}{ Geographic origin } & \multirow[b]{2}{*}{ Source $^{c}$} & \multicolumn{3}{|c|}{ GenBank accession no. ${ }^{a}$} \\
\hline & & & EF-1 $\alpha$ & BT & PHO \\
\hline 108 & Georgia & P. Colyer, this study & FJ466731 & FJ466736 & FJ466741 \\
\hline 110 & Arkansas & P. Colyer, this study & FJ466732 & FJ466737 & FJ466742 \\
\hline 127 & Arkansas & P. Colyer, this study & FJ466734 & FJ466739 & FJ466744 \\
\hline 140 & Arkansas & P. Colyer, this study & FJ466735 & FJ466740 & FJ466745 \\
\hline 112 & Arkansas & P. Colyer, this study & FJ466733 & FJ466738 & FJ466743 \\
\hline CA10, race 1 & Kern County, CA & Y. Kim/R. M Davis (18) & AY714099 & AY714084 & AY714114 \\
\hline ATCC 16421 , race 1 & United States & G. M. Armstrong & AY714104 & AY714090 & AY714118 \\
\hline ATCC 16611 , race 2 & United States & G. M. Armstrong & AY714105 & AY714091 & AY714119 \\
\hline ATCC 16612 , race 3 & Egypt & G. M. Armstrong & AY714106 & AY714092 & AY714120 \\
\hline CA11, race 3 & Tulare County, CA & Y. Kim/R. M Davis (18) & AY714100 & AY714085 & AY714115 \\
\hline CA 3 , race 3 & Tulare County, CA & S. N. Smith/J. E. DeVay (18) & AY714102 & AY714088 & AY714113 \\
\hline ATCC 16613 , race 4 & India & G. M. Armstrong & AY714107 & AY714093 & AY714121 \\
\hline CA14, race 4 & Fresno County, CA & Y. Kim/R. M. Davis (18) & AY714101 & AY714086 & AY714116 \\
\hline ATTC 36198, race 6 & Brazil & G. M. Armstrong & AY714103 & AY714089 & AY714117 \\
\hline 031665 , race 8 & China & K. O’Donnell (22) & AY714108 & AY714095 & AY714123 \\
\hline CA1, race 8 & Tulare County, CA & S. N. Smith/ J. E. DeVay (18) & AY714098 & AY714087 & AY714112 \\
\hline Aust16 & Cecil Plains, Australia & S. Bentley & AY714096 & AY714082 & AY714110 \\
\hline Aust19 & Boggabilla, Australia & S. Bentley & AY714097 & AY714083 & AY714111 \\
\hline FO1502 (nonpathogenic $F$. oxysporum) & California & R. M. Davis & AY714109 & AY714094 & AY714122 \\
\hline
\end{tabular}

\footnotetext{
${ }^{\mathrm{a}} \mathrm{EF}-1 \alpha=$ elongation factor, $\mathrm{BT}=\beta$-tubulin, and $\mathrm{PHO}=$ phosphate permase. Accession numbers beginning with AY previously published (18).

${ }^{\mathrm{b}}$ Culture collection numbers given for ATCC (American Type Culture Collection, Manassas, VA), and BBA (Biologische Bundesanstalt für Land-und Forstwirtschaft, Berlin, Germany), if applicable.

c Isolates from S. N. Smith/J. E. DeVay collected from 1975 to 1988. Isolates from P. Colyer collected from 2002 to 2007.
} 
tic pots filled with sterilized potting mix (50\% sphagnum peat moss, $50 \%$ washed sand, dolomite lime at $2.43 \mathrm{~kg} / \mathrm{cm}^{3}$, oyster shell lime at $0.872 \mathrm{~kg} / \mathrm{cm}^{3}$, superphosphate at $0.872 \mathrm{~kg} / \mathrm{cm}^{3}$, calcium nitrate at 0.344 $\mathrm{kg} / \mathrm{cm}^{3}$, potassium nitrate at $135 \mathrm{ml} / \mathrm{cm}^{3}$, and potassium sulfate at $90 \mathrm{ml} / \mathrm{cm}^{3}$ ). Fungal isolates representing races $1,3,4$, and 8 were CA10, CA3, CA14, and CA1, respectively (Table 2). The entire experiment was conducted twice (each repetition referred to as a trial).

Conidial suspensions of $F$. oxysporum $\mathrm{f}$. sp. vasinfectum were made from 2-weekold colonies grown on potato dextrose agar by flooding with sterile water, rubbing the surface of the agar with a glass rod, and filtering the spore suspension through four layers of cheesecloth. Conidial concentration was adjusted to $1 \times 10^{5}$ conidia $/ \mathrm{ml}$ with the aid of a hemacytometer. Twoweek-old seedlings were uprooted and dipped in the conidial suspension for 2 min. Controls were mock inoculated with water. Disease severity and vascular discoloration were measured approximately 4 weeks after inoculation. Individual plants were rated for disease severity based on the following scale: 1 , no symptoms; 2 , chlorosis or wilt restricted to cotyledons or the lowest true leaf; 3, similar symptoms but extending upward beyond the lowest true leaf; 4, severe symptoms affecting the whole plant; and 5, plant death (18). Vascular discoloration of stems cut at the soil line and sliced through the long axis was graded on the following scale: 1 , no symptoms; 2, light-brown streaks of vascular discoloration; 3, vascular discoloration prominent and dark brown; and 4, dark-

\section{-1 change}

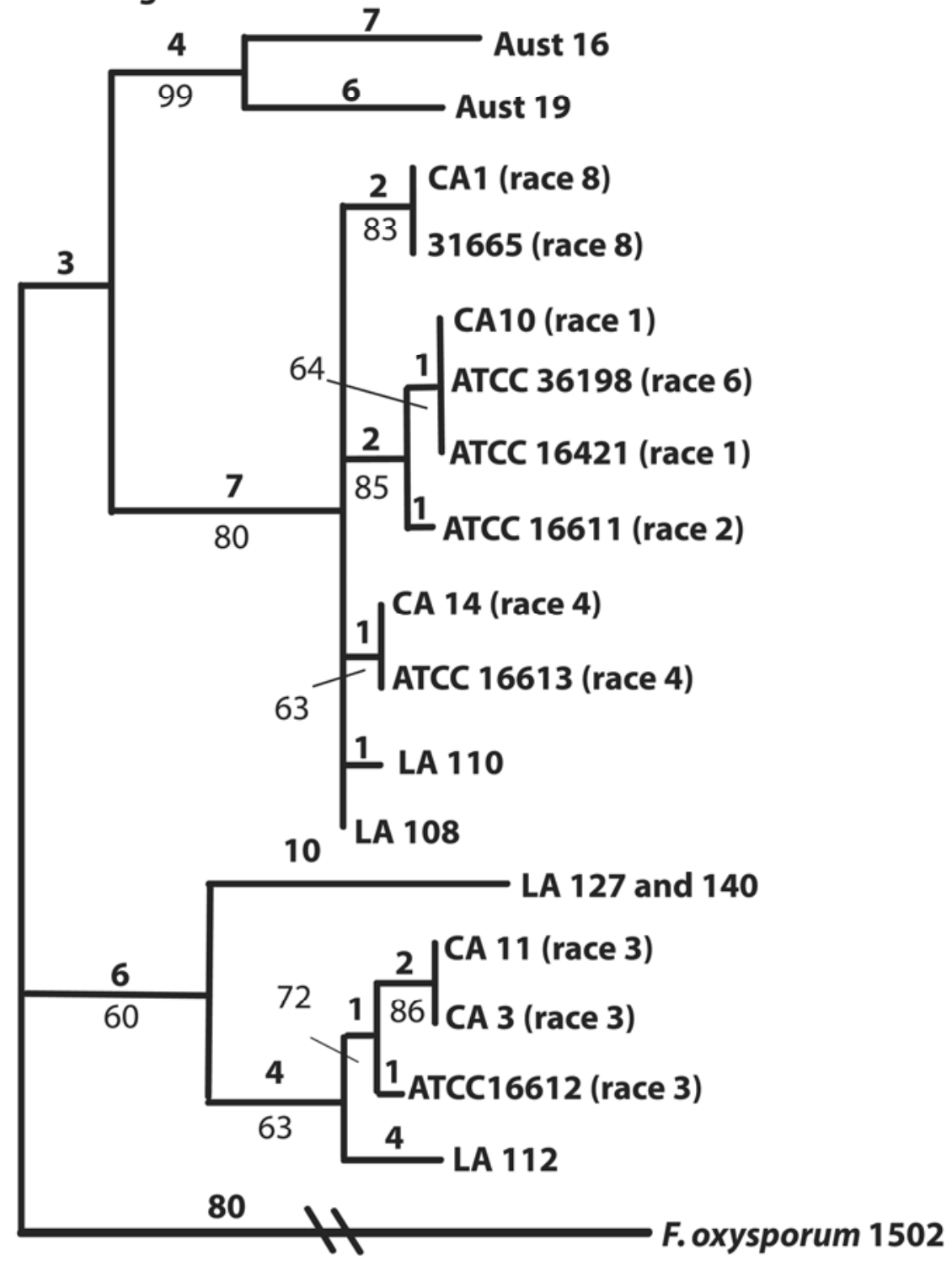

Fig. 1. Single most parsimonious tree from combined analysis of translational elongation factor, $\beta$ tubulin, and phosphate permase gene sequences $(\mathrm{CI}=0.9375, \mathrm{RI}=0.8788)$ from Fusarium oxysporum f. sp. vasinfectum isolates representing new and known lineages. A saprophytic $F$. oxysporum (isolate 1502 ) is used as the outgroup. Numbers of nucleotide changes are given above branches; bootstrap frequencies from 1,000 replications are noted below branches.

brown vascular discoloration accompanied by plant death. Plant height (from the soil surface to the mainstem terminal) and shoot dry weights (oven dried at $50^{\circ} \mathrm{C}$ for 3 to 4 days) were also measured. A 5- to 7$\mathrm{mm}$ piece of stem tissue was collected at harvest from about half of all plants, surface sterilized in $0.525 \%$ sodium hypochlorite, and plated on acidified potato dextrose agar to confirm presence of the isolates.

Data for each of the plant responses were evaluated using analysis of variance (ANOVA). Response variables of plant height and shoot dry weight were each examined using mixed models (PROC GLIMMIX, SAS release 9.2 ed.; SAS Institute, Cary, NC). In both analyses, fixed effects included cultivar, fungal isolate, and their interaction, and degrees of freedom were adjusted using the DDFM=KR option (SAS Institute 2008). Random effects included trial and block nested within trial. Because the individual plant was the experimental unit for both cultivar and fungal isolate, residual error was used in the denominator of all tests of fixed effects. Residual plots from the analysis of shoot dry weight indicated mild violations of the assumptions of normality and homogeneity of variance, which were corrected for the final analysis by squareroot transformation. For clarity, means of the dry weights are presented in the original untransformed metric. Because both analyses indicated significant cultivarisolate interactions, simple effects of isolate within cultivar and cultivar within isolate were examined using the SLICE option of the LSMEANS statement. When slices indicated significant differences among isolates within a cultivar or among cultivars within an isolate, the nature of the differences was examined by pairwise comparisons of the corresponding leastsquares means using the SLICEDIFF option of the LSMEANS statement (SAS Institute 2008). Within each family of comparisons, error degrees of freedom were row adjusted (the ADJDFE=ROW option) and the type I error rate was controlled at $\alpha=0.05$ by using the Bonferroni-Holm stepdown method (27).

Disease severity and vascular discoloration data were ordinal; thus, corresponding ANOVAs used the nonparametric approach of Shah and Madden (21). These analyses used the LD_CI.SAS macro (obtained at http://www.ams.med.uni-goettingen.de/de/ sof/ld/makros.html). For analyses of disease severity and vascular discoloration, fixed effects were cultivar, fungal isolate, and their interaction. Because the LD_CI macro does not accommodate random blocks or trials, each trial was analyzed separately using a completely randomized design structure. The nature of interactions between cultivar and isolate was examined by slices as previously described. Interpretation of treatment effects was based on 
relative effects output by the LD_CI macro for combinations of cultivar and fungal isolate. When slices indicated significant differences in relative effects among isolates within a cultivar or among cultivars within an isolate, pairs of relative effects were compared with single degree-offreedom contrasts using the pooled variance of the pair. These contrasts were collected into families of comparisons controlling family-wise type I error at $\alpha=$ 0.05 with the Bonferroni-Holm stepdown method as previously described. Because the relative effects are unitless and their magnitude is only interpretable in relation to other relative effects within the same analysis, median disease severity and vascular discoloration ratings are also provided for reference.

\section{RESULTS}

Phylogenetic analyses. Of the 61 isolates collected from the southern United States, 17 belonged to four novel genotypes (identified here as isolates 108, 110, 112 , and 127/140) based on comparisons of their EF-1 $\alpha$ sequences to those of characterized isolates (Table 1). Most (16 of 17) of the novel isolates were from Arkansas. Furthermore, most of the isolates from that state (16 of 27) were new genotypes. Ten of those isolates were genotypically identical to 108 , four were of the same genotype as 127 and 140, and the genotypes of isolates 110 and 112 were unique. Based on EF-1 $\alpha$ sequences, 21 of the 28 isolates from Louisiana were either race 1 or 2 and the remaining 8 isolates were races 3 or 8 . Of the four isolates from Georgia, one was of the same genotype as isolate 108. The two isolates from Missouri were race 8 .

The addition of the novel isolates to the phylogenetic analyses of EF- $1 \alpha$, phosphate permase, and $\beta$-tubulin genes did not change the overall tree topology previously reported (Fig. 1) (18,22). Genotypes represented by 108 and 110 were most similar to race 4 , and genotypes represented by 112 and 127/140 clustered near the race 3 branch.

Pathogenicity tests. All nine isolates of $F$. oxysporum f. sp. vasinfectum included in the pathogenicity assay caused at least mild disease symptoms. Because respective measures of plant height and shoot dry weight exhibited nearly identical patterns of response to each isolate, only the shoot dry weight data from the combined trials are presented. The identity of all isolates recovered from inoculated plants was confirmed by determining EF- $1 \alpha$ sequences. No F. oxysporum was recovered from noninoculated plants.

With the exception of cv. S 4357 inoculated with isolate 140, dry shoot weights of the Upland cultivars (Phytogen 72 and 480, DP 445, and S 4357) were reduced by races 1 and 8 and isolates 108, 110, 127, and 140 (Fig. 2). Shoot weights of Upland cultivars inoculated with isolate 112 and race 3 were not significantly different from the weights of the noninoculated plants. Race 4 significantly reduced shoot weights of Phytogen 480 but not the other three Upland cultivars.

Patterns of shoot weight responses of Pima cultivars (Phytogen 800 and DP 744) were different from those of Upland cultivars (Fig. 2). No isolate significantly reduced shoot weights of Phytogen 800 relative to the noninoculated plants. In contrast, shoot weights of DP 744 were significantly reduced by race 4 and isolate 108. With the exception of DP 744 inoculated with race 4 , the Upland cultivars were more severely impacted than the Pima cultivars by $F$. oxysporum f. sp. vasinfectum (Fig. 2).

Race 1 and isolates 108 and 110 caused significantly greater disease severity ratings in all Upland cultivars than the corresponding noninoculated plants (Fig. 3A and $\mathrm{B})$. In contrast, neither race 3 nor isolate 112 caused significant disease symptoms in any Upland cultivar. Responses of DP 445 to isolate 127 and Phytogen 480 to race 8 were variable between the trials. In both trials, race 4 caused symptoms of greater magnitude in Phytogen 480 relative to the noninoculated plants and caused significant disease symptoms in Phytogen 72 in one of the two trials. Isolate 140 caused significantly greater disease symptoms in all Upland cultivars, except in $\mathrm{S}$ 4357 , than in the corresponding noninoculated plants.

Responses of Pima cv. Phytogen 800 to isolates of $F$. oxysporum $\mathrm{f}$. sp. vasinfectum differed between the two trials (Fig. 3A and B). In trial 1, all $F$. oxysporum f. sp. vasinfectum races and isolates except race 3 and isolate 140 caused mild symptom expression in Phytogen 800. In trial 2, no genotype of the fungus caused significant disease symptoms in Phytogen 800. Cv. DP 744 exhibited similar symptom expression in both trials and was most severely affected by race 4 , which often caused plant death. Although no clear pattern of disease symptoms differentiated the Upland and Pima cultivars for all races and isolates, neither type of cotton was severely impacted by race 3 or isolate 112 in either trial. In general, symptom expression was greater in DP 744 than in Phytogen 800.

Trends in the relative effects on vascular discoloration due to inoculation with $F$.

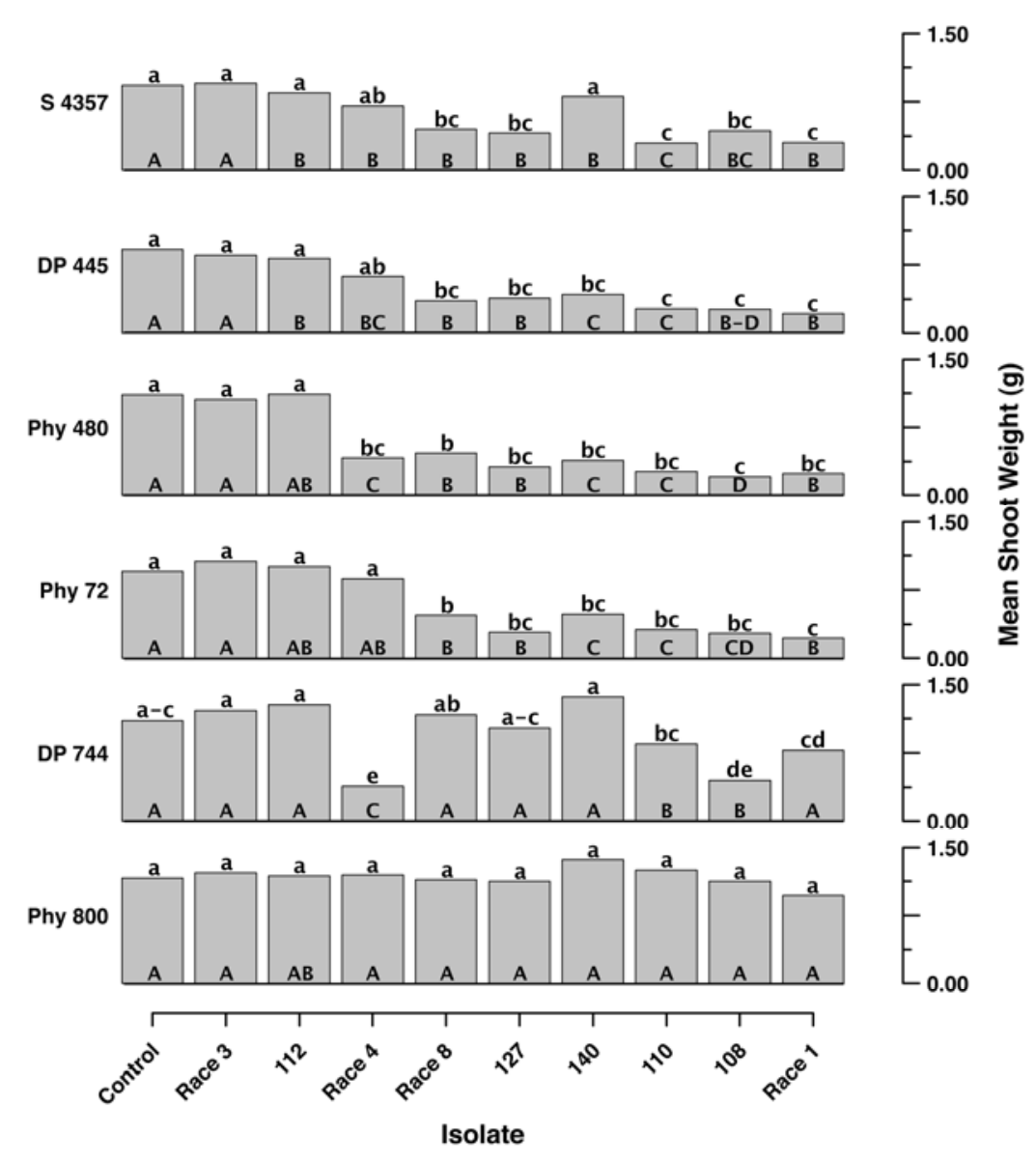

Fig. 2. Pairwise comparisons of plant shoot dry weight among isolates within cultivars (lowercase letters, compared horizontally) and among cultivars within a given isolate (uppercase letters, compared vertically). Data from two trials were combined and all possible pairwise comparisons were made of the least squared means. Type I error rate was controlled at $\alpha=0.05$ using the Bonferroni-Holm stepdown method (27). Means with the same letter are not significantly different. Isolates representing races $1,3,4$, and 8 were CA10, CA3, CA14, and CA1, respectively. 
oxysporum f. sp. vasinfectum were almost identical to those for disease severity. In both trials, neither race 3 nor isolate 112 caused significant vascular discoloration in any Upland cultivar relative to the noninoculated plants (Fig. 4A and B). Race 1 and isolates 108, 110, 127, and 140 generally caused greater vascular discoloration in all Upland cultivars than that of the noninoculated plants. Race 4 caused significant vascular discoloration in Phytogen 480 and Phytogen 72 in the first trial; oth-

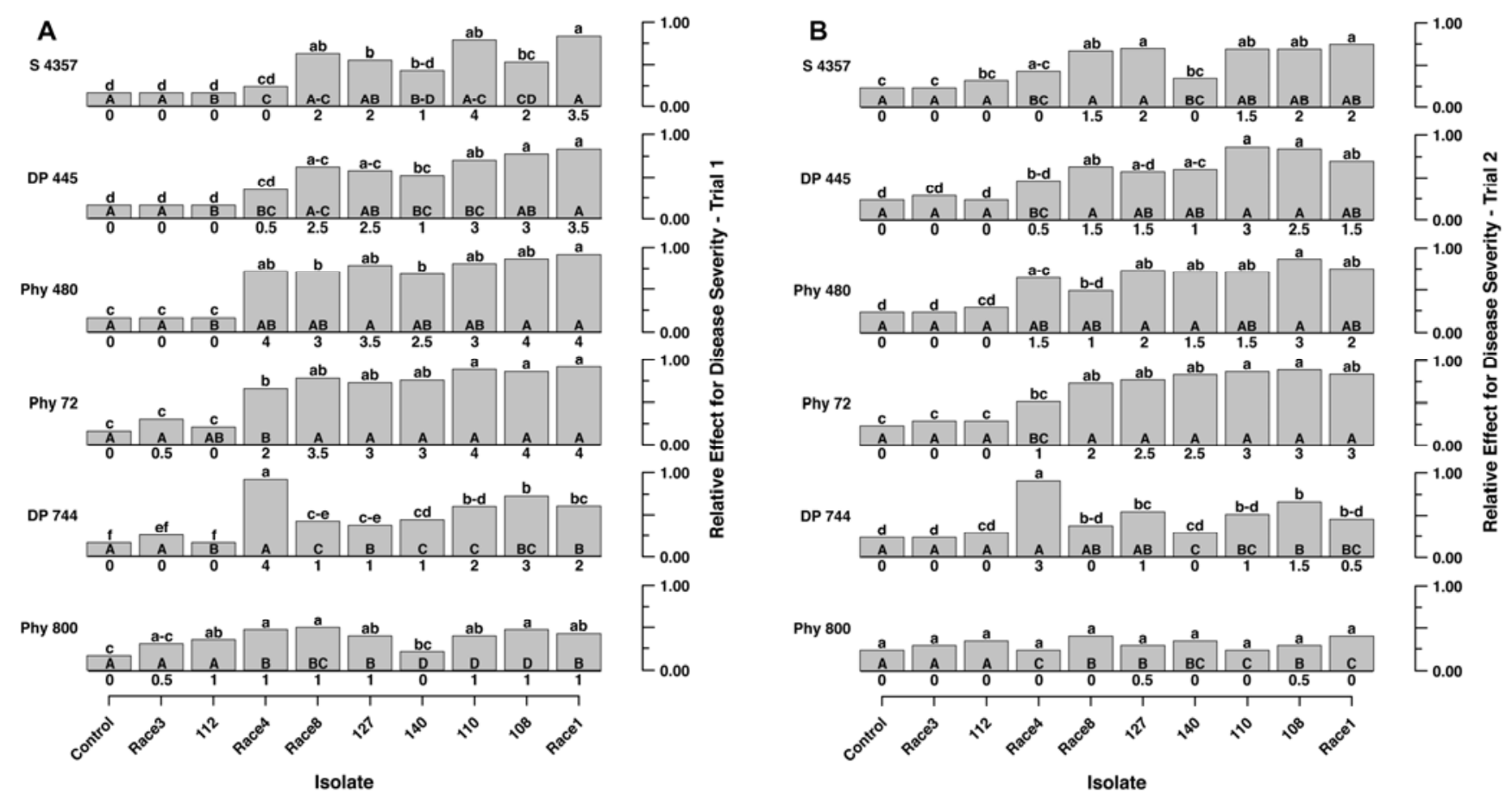

Fig. 3. Pairwise comparisons of disease severity from A, trial 1 and $\mathbf{B}$, trial 2 among isolates within cultivars (lowercase letters, compared horizontally) and among cultivars within a given isolate (uppercase letters, compared vertically). All possible pairwise comparisons were made of the relative effects estimated by the LD_CI.SAS macro (21). Type I error rate was controlled at $\alpha=0.05$ using the Bonferroni-Holm stepdown method (27). Relative effects with the same letter are not significantly different. Numbers below shaded bars denote median disease severity rating for isolates. Disease severity was based on the scale of 1 , no symptoms; 2, chlorosis or wilt restricted to cotyledons or the lowest true leaf; 3 , similar symptoms but extending upward beyond the lowest true leaf; 4 , severe symptoms affecting the whole plant; and 5, plant death.

A

S 4357

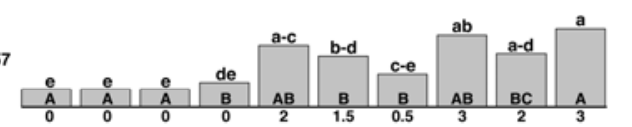

DP 445

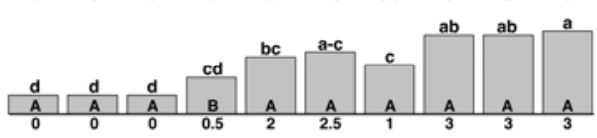

Phy 480

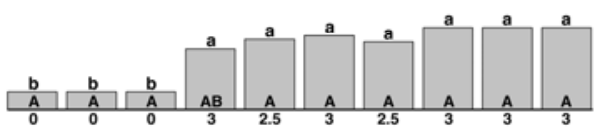

Phy 72
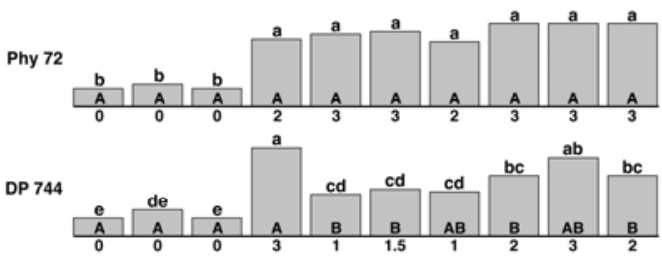

Phy 800

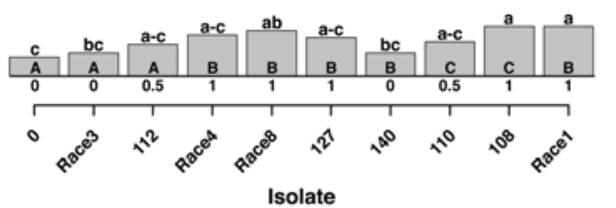

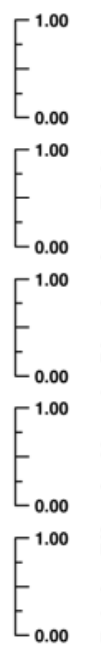

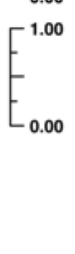

B

S 4357

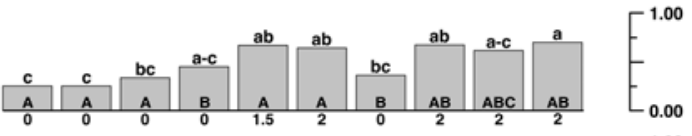

DP 445
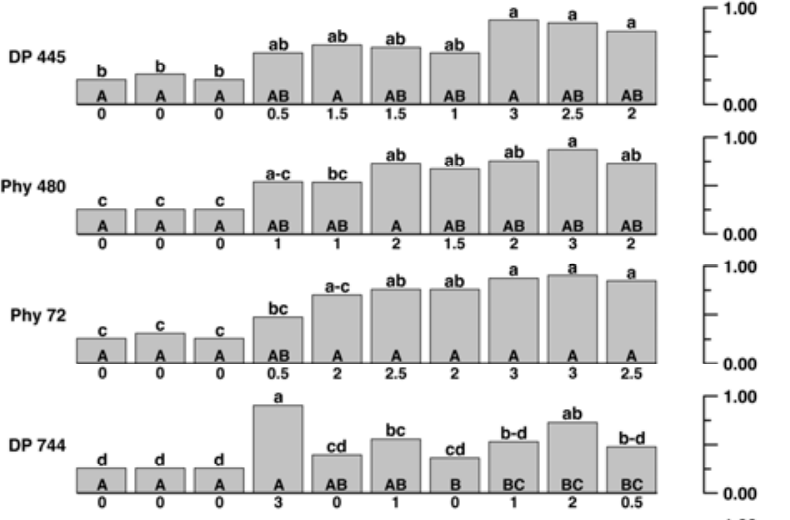

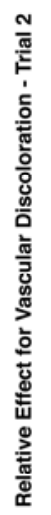

Phy 800

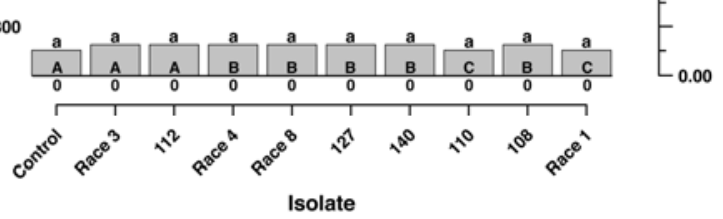

Fig. 4. Pairwise comparisons of vascular discoloration from $\mathbf{A}$, trial 1 and $\mathbf{B}$, trial 2 among isolates within cultivars (lowercase letters, compared horizontally) and among cultivars within a given isolate (uppercase letters, compared vertically). All possible pairwise comparisons were made of the relative effects estimated by the LD_CI.SAS macro (21). Type I error rate was controlled at $\alpha=0.05$ using the Bonferroni-Holm stepdown method (27). Relative effects with the same letter are not significantly different. Numbers below shaded bars denote median vascular discoloration rating for isolates. Vascular discoloration of stems was based on the scale of 1, no symptoms; 2, light-brown streaks of vascular discoloration; 3, vascular discoloration prominent and dark brown; and 4, dark-brown vascular discoloration accompanied by plant death. 
erwise, race 4 did not significantly increase vascular discoloration in the Upland cultivars.

In general, vascular discoloration ratings for Pima cv. Phytogen 800 were relatively low (Fig. 4A and B). In trial 1, races 1 and 8 and isolate 108 caused vascular discoloration in Phytogen 800; in trial 2, no genotype of $F$. oxysporum f. sp. vasinfectum caused significant vascular discoloration in Phytogen 800. In contrast, race 4 and isolates 108 and 127 caused significant vascular discoloration in DP 744 in both trials. Races 1 and 8 and isolates 110 and 140 caused vascular discoloration of greater magnitude than the noninoculated DP 744 plants in trial 1 but not trial 2. In both trials, race 3 and isolate 112 did not cause significant vascular discoloration in DP 744 plants.

\section{DISCUSSION}

Four novel genotypes of $F$. oxysporum $\mathrm{f}$. $\mathrm{sp}$. vasinfectum from the southeastern United States were discovered in this study. Unexpectedly, the novel genotypes were not rare and composed the majority of the isolates collected from Arkansas. Isolates representative of race 3 and race 8 were also found for the first time in the United States outside of California. These results are in marked contrast to the last domestic survey of races causing Fusarium wilt of cotton (16). In 1983, Kappelman differentiated 53 isolates from the southern United States into race 1 or race 2, the latter of which is now considered to be a variant of race $1(13,22)$. Results of this study suggest that diversity of $F$. oxysporum f. sp. vasinfectum present in the United States has increased significantly from the time of Kappelman's survey. Because $F$. oxysporum f. sp. vasinfectum can be seedborne $(3,8,12)$, the possibility that these genotypes may spread to noninfested areas is cause for concern.

Three of the new genotypes, represented by 108,110 , and $127 / 140$, were clearly distinct from known races in our phylogenetic analysis, and all were pathogenic to cotton. However, none could be consistently differentiated from each other or from races 1 and 8 based on their ability to cause disease on our selection of cultivars. Isolate 112 had small sequence variations from previously characterized race 3 isolates and was similar to race 3 in pathogenicity tests. Both caused mild symptoms on the selected cultivars. Race 3 is the predominant cause of Fusarium wilt in Israel, where it causes economic losses (17). In contrast, it apparently causes little or no yield loss in the United States, possibly because a highly susceptible cultivar is not grown.

A set of differential cotton cultivars needs to be established to clarify the current race structure for $F$. oxysporum f. sp. vasinfectum and characterize the new genotypes reported in the southeastern
United States. In this study, the use of race to label well-known isolates and to maintain continuity in the literature is continued. However, the use of "race" to identify new genotypes of $F$. oxysporum f. sp. vasinfectum is not considered valid because distinct resistance genes capable of separating isolates in pathogenicity tests have not been identified. To date, combinations of Gossypium cultivars to unambiguously discriminate new races have not been assembled. For example, the Australian genotypes of $F$. oxysporum f. sp. vasinfectum, which are phylogenetically distinct from other lineages, appear identical to race 6 when tested on one differential cultivar panel for $F$. oxysporum f. sp. vasinfectum (11). To our knowledge, a differential cultivar capable of identifying the Australian genotypes has yet to be identified. The cultivars used in this study varied in their ability to discriminate among the genotypes of $F$. oxysporum f. sp. vasinfectum but, collectively, they were not able to discriminate all genotypes. Pima cv. Phytogen 800 was fairly resistant to all isolates and, overall, the Upland cvs. DP 445 and Phytogen 480 and 72 showed similar patterns of susceptibility. Of the cultivars tested, DP 744 was the only cultivar exhibiting extreme susceptibility to race 4 . We are not yet formally naming the new genotypes from the southeastern United States because this is a first report of several new isolates and the potential for confusion exists for descriptors of pathotypes in $F$. oxysporum f. sp. vasinfectum. For example, races 1 and 2 have been variously called lineage II (22) or race A $(7,13)$. In future studies, we will attempt to discriminate these lineages further by screening additional Gossypium germplasm as well as analyzing more isolates of $F$. oxysporum f. sp. vasinfectum using additional markers.

\section{ACKNOWLEDGMENTS}

We thank Cotton Incorporated California State Support Committee for providing partial financial support, and B. Mackey and D. Shah for statistical support and suggestions.

\section{LITERATURE CITED}

1. Abd-Elsalam, K. A., Omar, M. R., Migheli, Q., and Nirenberg, H. I. 2004. Genetic characterization of Fusarium oxysporum f. sp. vasinfectum isolates by random amplification of polymorphic DNA (RAPD) and amplified fragment length polymorphism (AFLP). J. Plant Dis. Prot. 111:534-544.

2. Abo, K., Klein, K. K., Edel-Hermann, V., Gautheron, N., Traore, D., and Steinberg, C. 2005. High genetic diversity among strains of Fusarium oxysporum f. sp. vasinfectum from cotton in Ivory Coast. Phytopathology 95:1391-1396.

3. Allen, S. J., and Kochman, J. K. 2001. Eliminating seed-borne inoculum of Fusarium oxysporum f. sp. vasinfectum in cotton. Pages 139-140 in: Beltwide Cotton Conf. Natl. Cotton Counc. Am. Memphis, TN and Anaheim, CA.

4. Armstrong, G. M., and Armstrong, J. K. 1960. American, Egyptian, and Indian cotton-wilt fusaria: their pathogenicity and relationship to other wilt fusaria. U. S. Dep. Agric. Tech. Bull. 1219:1-19.

5. Armstrong, G. M., and Armstrong, J. K. 1978 A new race (race 6) of the cotton-wilt Fusarium from Brazil. Plant Dis. Rep. 62:421-423.

6. Armstrong, J. K., and Armstrong, G. M. 1958. A race of the cotton-wilt Fusarium causing wilt of Yelredo soybean and flue-cured tobacco. Plant Dis. Rep. 42:147-151.

7. Assigbetse, K. B., Fernandez, D., Dubois, M. P., and Geiger, J. P. 1994. Differentiation of Fusarium oxysporum f. sp. vasinfectum races on cotton by random amplified polymorphic DNA (RAPD) analysis. Phytopathology 84:622-626.

8. Bennett, R. S., Hutmacher, R. B., and Davis, R. M. 2008. Seed transmission of Fusarium oxysporum f. sp. vasinfectum race 4 in California. J. Cotton Sci. 12:160-164.

9. Bridge, P. D., Ismail, M. A., and Rutherford, M. A. 1993. An assessment of aesculin hydrolysis, vegetative compatibility and DNA polymorphism as criteria for characterizing pathogenic races within Fusarium oxysporum f. sp. vasinfectum. Plant Pathol. 42:264-269.

10. Chen, Q., Ji, X., and Sun, W. 1985. Identification of races of cotton wilt Fusarium in China. Agric. Sci. China 6:1-6.

11. Davis, R. D., Moore, N. Y., and Kochman, J. K. 1996. Characterisation of a population of Fusarium oxysporum f. sp. vasinfectum causing wilt of cotton in Australia. Aust. J. Agric. Res. 47:1143-1156.

12. Elliott, J. A. 1923. Cotton-wilt, a seed-borne disease. J. Agric. Res. 23:387-394.

13. Fernandez, D., Assigbetse, K., Dubois, M. P., and Geiger, J. P. 1994. Molecular characterization of races and vegetative compatibility groups in Fusarium oxysporum f. sp. vasinfectum. Appl. Environ. Microbiol. 60:4039-4046.

14. Hering, O., Nirenberg, H. I., Köhn, S., and Deml, G. 1999. Characterization of isolates of Fusarium oxysporum Schlecht. f. sp. vasinfectum (Atk.) Snyd. \& Hans., races 1-6, by cellular fatty acid analysis. J. Phytopathol. 147:509514.

15. Ibrahim, F. M. 1966. A new race of the cottonwilt Fusarium in the Sudan Gezira. Emp. Cotton Grow. Rev. 43:296-299.

16. Kappelman, A. J. 1983. Distribution of races of Fusarium oxysporum f. sp. vasinfectum within the United States. Plant Dis. 67:12291231.

17. Katan, T., and Katan, J. 1988. Vegetativecompatibility grouping of Fusarium oxysporum f. sp. vasinfectum from tissue and the rhizosphere of cotton plants. Phytopathology 78:852-855.

18. Kim, Y., Hutmacher, R. B., and Davis, R. M. 2005. Characterization of California isolates of Fusarium oxysporum f. sp. vasinfectum. Plant Dis. 89:366-372.

19. O'Donnell, K., Kistler, H. C., Cigelnik, E., and Ploetz, R. C. 1998. Multiple evolutionary origins of the fungus causing Panama disease of banana: concordant evidence from nuclear and mitochondrial gene genealogies. Proc. Natl. Acad. Sci. USA 95:2044-2049.

20. O'Donnell, K., Kistler, H. C., Tacke, B. K., and Casper, H. H. 2000. Gene genealogies reveal global phylogeographic structure and reproductive isolation among lineages of Fusarium graminearum, the fungus causing wheat scab. Proc. Natl. Acad. Sci. USA 97:7905-7910

21. Shah, D. A., and Madden, L. V. 2004. Nonparametric analysis of ordinal data in designed factorial experiments. Phytopathology 94:3343.

22. Skovgaard, K., Nirenberg, H. I., O'Donnell, K., and Rosendahl, S. 2001. Evolution of Fusarium oxysporum f. sp. vasinfectum races inferred from multigene genealogies. Phytopathology 91:1231-1237.

23. Tooley, P. W., Goley, E. D., Carras, M. M., 
Frederick, R. D., Weber, E. L., and Kuldau, G. A. 2001. Characterization of Claviceps species pathogenic on sorghum by sequence analysis of the $\beta$-tubulin gene intron 3 region and EF-1 $\alpha$ gene intron 4. Mycologia 93:541551.

24. Ulloa, M., Hutmacher, R. B., Davis, R. M., Wright, S. D., Percy, R., and Marsh, B. 2006.
Breeding for Fusarium wilt race 4 resistance in cotton under field and greenhouse conditions. J. Cotton Sci. 10:114-127.

25. USDA Agricultural Marketing Service. 2008. Cotton varieties planted: 2008 crop. USDAAMS, Cotton Program, publ. mp_cn833.

26. Wang, B., Brubaker, C. L., Tate, W., Woods, M. J., and Burdon, J. J. 2008. Evolution of virulence in Fusarium oxysporum f. sp. vasinfectum using serial passage assays through susceptible cotton. Phytopathology 98:296303.

27. Westfall, P. H., Tobias, R. D., Rom, D., Wolfinger, R. D., and Hochberg, Y. 1999. Multiple Comparisons and Multiple Tests Using SAS. SAS Institute, Cary, NC. 